\title{
Interaction of rotary working body of roller type with the object of processing
}

\author{
Sergey K. Papusha ${ }^{1, *}$, Azamat E. Bogus ${ }^{1}$, and Vladimir I. Konovalov ${ }^{1}$ \\ ${ }^{1}$ Federal State Budgetary Educational Institution of Higher Education "Kuban State Agrarian \\ University named after I.T. Trubilin”, Krasnodar, Russian Federation
}

\begin{abstract}
There was presented the constructive-technological scheme of leaf-separating apparatus for harvesting tobacco leaves in the article. There was conducted the theoretical analysis of the process of tobacco leaf separation from a stalk. There were obtained the dependencies characterizing the trajectory and speed of arbitrary point of the cutting edge of a small drum.
\end{abstract}

Tobacco is one of the most labour-intensive crops in crop production. At the present time one of the most urgent tasks is mechanization of per leaf harvesting of tobacco, which in its turn is one of the most labor-intensive from the whole list of technological operations in tobacco growing $[1,2]$. In order to further improve the efficiency of tobacco growing, it is necessary to continuously improve the profitability of tobacco production, which is not possible without the use and development of machine technologies [3]. As tiered maturation of tobacco leaves on the stalk, they are usually removed in several stages or so called break-ups. In tobacco growing the mechanized harvesting of tobacco leaves is carried out in two stages: harvesting of middle and upper break-ups $[4,5]$. By present time a number of machines for tobacco leaf harvesting have been developed [6, 7]. However the applied leaf-separating apparatuses have some disadvantages which do not supply with present agro-technological requirements demanding much of technological process of domestic tobacco variety harvesting. Use of leaf-separating apparatuses working with the use of rotating small drums with sharpened cutting edges fixed on chain contours as well as with equipped pneumatic system and holding rollers in harvesters allows increasing the completeness of leaf separation and decrease of leaf plate injury due to the rapid removal of leaves from the leaf separation area. The apparatus for separating tobacco leaves $[8,9]$ (Figure 1) includes two supporting chain contours 1 of infinite type, with small drums 2 having sharpened blades (cutting edges) and installed in the bearing supports 4 mounted on the bolts 5 , as well as for rotating the small drums of sprocket 6 and additional chain contours 7 . The apparatus is supplied with two rollers 8 , mounted at angle relatively to the level and each other and having rotations towards each other. On every roller there was made the spiral surface 9. The drums form cells in the leaf-separation area 10. A pneumatic system is installed above the machine, which includes a delivery fan and a pair of air ducts with nozzles 11. The nozzles are installed in the air ducts along the longitudinal axis of the

\footnotetext{
* Corresponding author: serega0318@mail.ru
} 
device and at an angle to it. Through the nozzle, the air flow is directed to the leaves of tobacco, directly to the center of its gravity, which allows you to orient them in a horizontal position and press to the cutting edges of the drums. The apparatus for separating the leaves is as follows. When it moves along a row, the stalk enters the working channel formed by two rolls 8 and helical wound 9. Due to the rotation of the rollers, the tobacco stalk is oriented and covered by cell 10 . Thus air ducts through nozzles 11 direct an air stream from the fan on plates of the separated leaves, thereby pressing them to cutting edges 3 of drums 2. Cutting edges 4 of rotating small drums 3 is made by leaf separation forming in working area of a cell, which are moved along a tobacco stalk if to install the apparatus forward.

To orient the stalk, it is necessary to correlate the speed of movement, the frequency of rotation and the angle of inclination of the rollers, the lifting angle of the wound and other parameters [10]. At the same time, of course, the necessary condition is the movement of the harvester along the row, i.e. preservation of the course stability $[11,12,13]$. Such combination of factors will allow to observe the set technological efficiency and reliability of technological process, and as a consequence and economic efficiency $[14,15,16,17]$.

According to the design and technological scheme in Figure 1, the separation of the leaf from the stem of tobacco is produced by cutting small drums that move in a closed chain contour at a speed of $\mathrm{V}$ p.a., they have axial rotation $\omega_{\sigma}$ due to the additional contour. At the same time, the movement of the machine along the row with скоростью $\mathrm{V}_{\mathrm{M}}$ that also brings components in the cutting force of the blade edge of a small drum. For a high-quality cut of the tobacco leaf, it is necessary to analyze the interaction between the cutting drum and the tobacco leaf, which will further determine the cutting force $R_{\sigma}$, since it will determine the force of the anti-cutting part (the force of the airflow $\mathrm{F}_{\text {дав }}$ to hold the leaf).

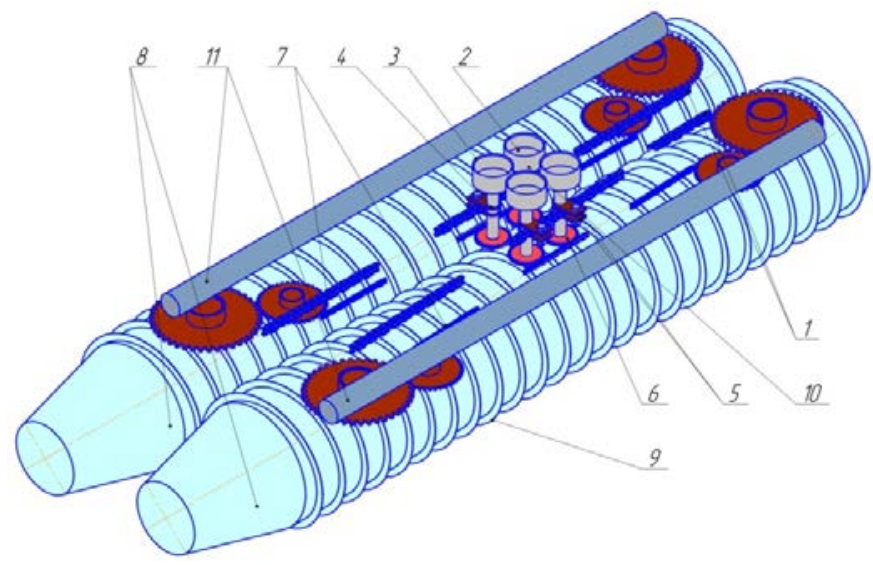

Fig. 1. Apparatus of tobacco leaf separation. 1 - chain contour; 2 - small drum; 3 - cutting edge of a small drum; 4 - ball bearing; 5 - pin; 6 -sprocket; 7 - additional chain contour; 8 - roller; 9 - helical surface of roller; 10 - leaf-separating cell; 11 - air duct with nozzles.

Analysis of interaction of the cutting small drum with the tobacco leaf will begin with the making of the trajectory of movement of an arbitrary point B of the edge of the drum blade for an arbitrary period of time $t$. To do this, take the coordinate system as shown in Figure 2. 

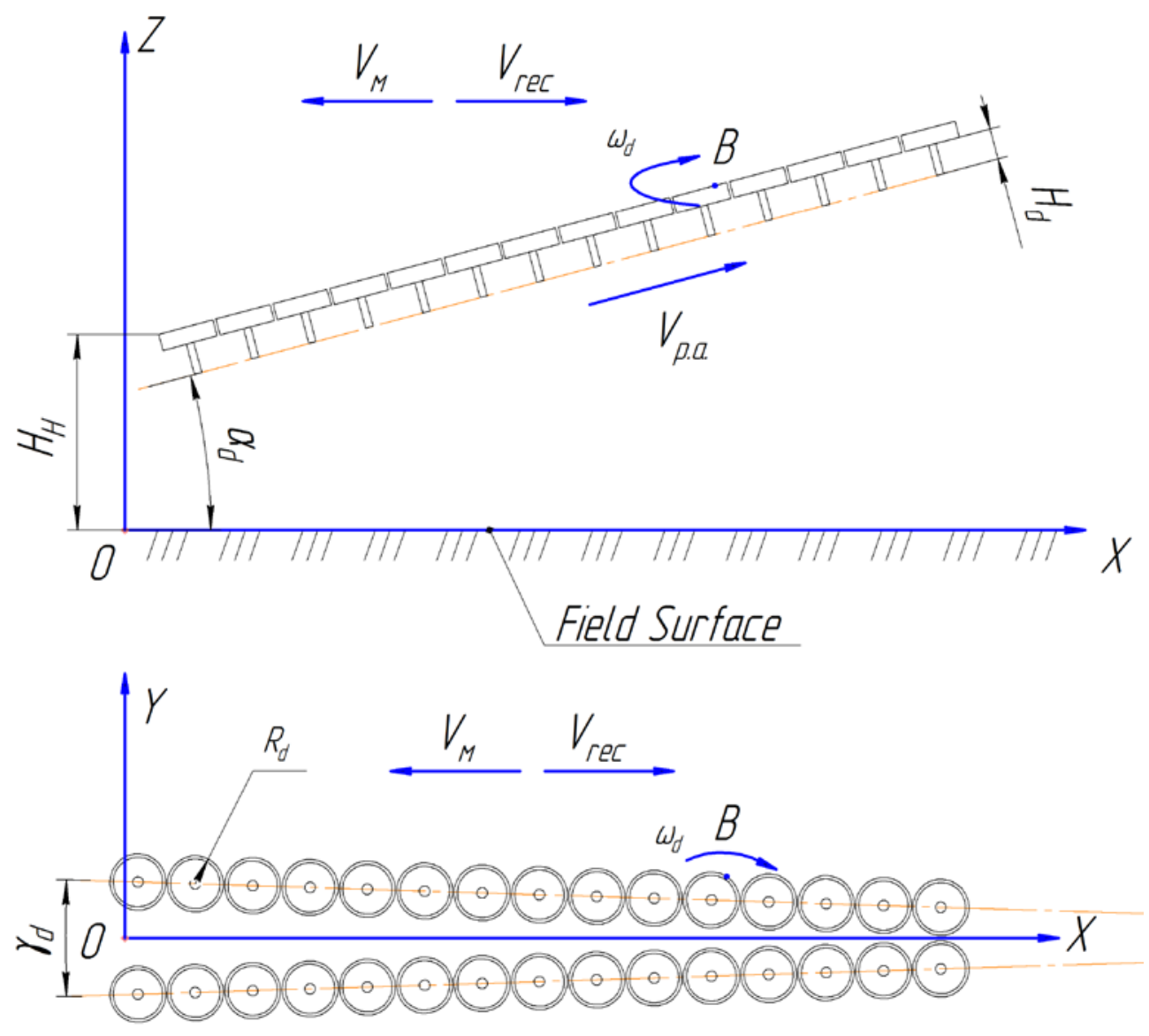

Fig. 2. Scheme of trajectory of movement of the edge of blade of cutting small drum of leafseparating apparatus.

So, the movement of the point $\mathrm{B}$ is described by equations:

$$
\left\{\begin{array}{l}
X_{B}=V_{\text {rec }} t+V_{p . a .} t \cos \alpha_{d}+R_{d} \sin \omega_{d} t \cdot \cos \alpha_{d}, \\
Y_{B}=V_{\text {rec }} t \cos \gamma_{d}+R_{d} \sin \omega_{d} t, \\
Z_{B}=H_{H}+V_{p . a .} t \sin \alpha_{d}+R_{d} \sin \omega_{d} t \cdot \sin \alpha_{d} .
\end{array}\right.
$$

where $V_{\text {rec }}$ - speed of tobacco stalk delivery to the leaf separation area which is equal to the speed of the machine $V_{\text {rec }}=V_{M}, \mathrm{~m} / \mathrm{s}$;

$V_{\text {p.a. }}-$ speed of small drum travel along chain contour, $\mathrm{m} / \mathrm{s}$;

$\alpha_{d}$ - angle of small drum installation to the surface of land, degree;

$R_{d}$ - radius of cutting edge of small drum, $\mathrm{m}$;

$\omega_{d}-$ angle speed of a small drum rotation, $\mathrm{rad} / \mathrm{s}$ :

$\gamma_{d}$ - angle of small drum installation towards each other, degree;

$H_{d}$ - height of a small drum installation relatively to a roller, m;

$H_{H}$ - height of installation of a small drum relatively to the land surface (height of break-up beginning), $\mathrm{m}$.

Differentiated the system of equations (1) by time $t$, it turned: 


$$
\left\{\begin{array}{l}
V_{X_{B}}=\frac{d X_{B}}{d t}=V_{r e c}+V_{p . a .} \cos \alpha_{d}+R_{d} \cos \alpha_{d} \cdot \omega_{d} \cos \omega_{d} t \\
V_{Y_{B}}=\frac{d Y_{B}}{d t}=V_{r e c} \cos \gamma_{d}+R_{d} \omega_{d} \cos \omega_{d} t \\
V_{Z_{B}}=\frac{d Z_{B}}{d t}=V_{p . a .} \sin \alpha_{d}+R_{d} \sin \alpha_{d} \cdot \omega_{d} \cos \omega_{d} t .
\end{array}\right.
$$

The expression (2) shows the projection of the absolute speed of an arbitrary point B in the axis of coordinates. Then the absolute speed of optional point B of the cutting drum blade edge will be determined by the expression:

$$
V_{B}=\sqrt{V_{X_{B}}^{2}+V_{Y_{B}}^{2}+V_{Z_{B}}^{2}}
$$

So, present expressions (3) after transformation will be equal:

$$
\begin{gathered}
V_{X_{B}}^{2}=V_{r e c}^{2}+V_{p . a .}^{2} \cos ^{2} \alpha_{d}+R_{d}^{2} \cos ^{2} \alpha_{d} \cdot \omega_{d}^{2} \cos ^{2} \omega_{d} t+2 V_{r e c} V_{p . a .} \cos \alpha_{d}+ \\
+2 V_{r e c} R_{d} \cos \alpha_{d} \cdot \omega_{d} \cos \omega_{d} t+2 V_{p . a .} \cos \alpha_{d} R_{d} \cos \alpha_{d} \cdot \omega_{d} \cos \omega_{d} t \\
V_{Y_{B}}^{2}=V_{r e c}^{2} \cos ^{2} \gamma_{d}+R_{d}^{2} \omega_{d} \cos ^{2} \omega_{d} t+2 V_{r e c} \cos \gamma_{d} \cdot R_{d} \omega_{d} \cos \omega_{d} t, \\
V_{Z_{B}}^{2}=V_{p . a .}^{2} \sin ^{2} \alpha_{d}+R_{d}^{2} \sin ^{2} \alpha_{d} \cdot \omega_{d} \cos ^{2} \omega_{d} t+ \\
+2 V_{p . a .} \sin \alpha_{d} \cdot R_{d} \sin \alpha_{d} \cdot \omega_{d} \cos \omega_{d} t
\end{gathered}
$$

Show $A=R_{d} \omega_{d} \cos \omega_{d} t$. After substitution and transformations of expressions $(4,5,6)$ into expression (3), taking into account the replacement, we obtain:

$$
V_{B}=\sqrt{A^{2}+2 V_{p . a .} A+2 V_{\text {rec }}\left(\cos \alpha_{d}+\cos \gamma_{d}\right) A+V_{\text {rec }}^{2}\left(1+\cos ^{2} \gamma_{d}\right)+V_{p . a .}^{2}+2 V_{\text {rec }} V_{p . a .} \cos \alpha_{d}} .
$$

The expression (7) shows the dependence of absolute speed of the optional point $B$ of the blade edge of small drum dependent on constructive and security parameters. From expression (7) we can see that the formation of absolute speed of blade edge of small drum is influenced the speed of movement of small drums $V_{p . a}$ along chain contour, speed of delivery of tobacco stalk $V_{\text {rec }}$ in the area of leaf separation, radius $R_{d}$ of cutting edge of a small drum and angle speed $\omega_{d}$ of a small drum rotation.

It is important to note that when separating the tobacco leaf from the stalk we should supervise for the garbage from the area of leaf separation, which will be characterized by the direction of the absolute speed of an arbitrary point $B$. Change of the direction of the vector of absolute speed of a point $B$ is characterized by the guides of the cosines. For a more convenient analysis, it is better to represent the angle between the coordinate axes and the vector of absolute velocity vector in terms:

$$
\left(V_{B} \wedge i\right)=\operatorname{arcos} \frac{V_{X_{B}}}{V_{B}}, \quad\left(V_{B} \wedge j\right)=\operatorname{arcos} \frac{V_{Y_{B}}}{V_{B}}, \quad\left(V_{B} \wedge k\right)=\operatorname{arcos} \frac{V_{Z_{B}}}{V_{B}},
$$

where $i, j, k$ - single vectors of coordinate axis.

$$
\text { Specify: }\left(V_{B} \wedge i\right)=\varphi_{X},\left(V_{B} \wedge j\right)=\varphi_{Y},\left(V_{B} \wedge k\right)=\varphi_{Z},
$$


To obtain a visual representation of the nature of the change in the absolute velocity of the point $\mathrm{B}$ in the area of leaf separation, it is necessary to construct graphs (Figure 3) of the change in the magnitude of the absolute velocity and absolute velocity projections on the coordinate axes when changing the angle of rotation of the small drum.

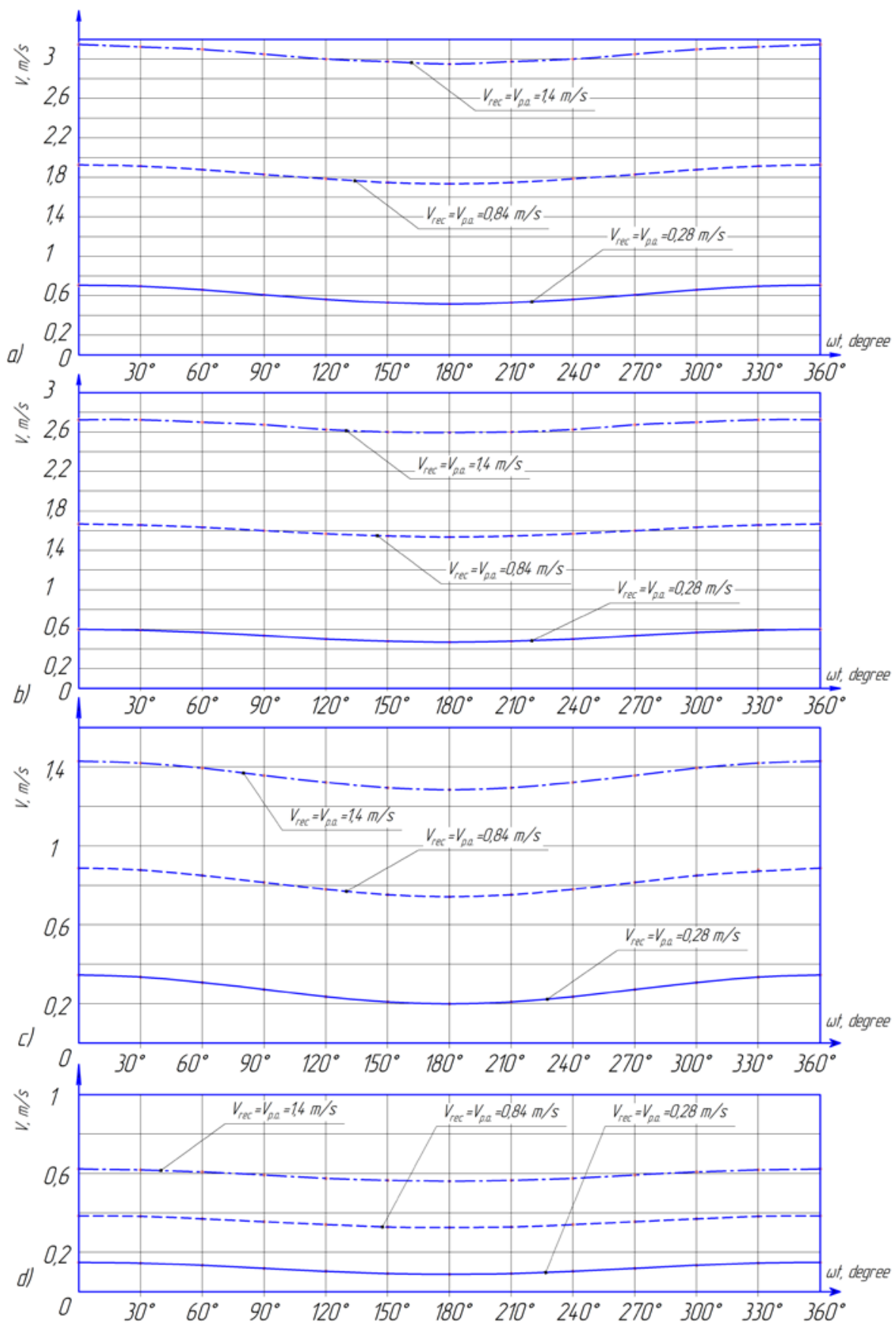

Fig. 3. Graph of the change of absolute velocity of the point B in the leaf separation area: $a-$ absolute velocity, $b$ - by axis $O X, c-$ by axis $O Y, d$ - by axis $O Z$ 
In Figure 3 the graphs were made with the following constructive and regime parameters: $A B=25^{\circ}, R_{d} 0,072 \mathrm{~m}, U B=14^{\circ}, \omega_{d}=1,01 \mathrm{~s}-1$. The graph (Figure 3,a) of the change of absolute velocity of the point $B$ in the leaf separation area shows that at the coincidence of the direction of movement of drums on the chain contour $V_{p . a}$. and the angle of rotation of the small drum in the range of $180^{\circ}-360^{\circ}$ the absolute speed grows along a curvilinear dependence and reaches a maximum in the top point in coincidence with the axis $O X$, and accordingly the absolute speed falls in the range $0^{\circ}-180^{\circ}$ and reaches the minimum at the lowest point in coincidence with the axis $O X$. When increasing the feed rate of the $V_{r e c}$, i.e. the speed of the car, the change in speed begins to approach to the linear dependence, but the nature of its changes are not significantly changed, and the absolute value is changed.

After analyzing the obtained graphs, it can be concluded that the increase in the productivity of the machine can be due to an increase in the feed rate of the $V_{\text {rec }}$, i.e. an increase in the growth of the movement of the machine, while significant crop losses due to a decrease in the full collection will not be observed.

\section{Conclusions}

1. The article presents a constructive and technological scheme of the machine for harvesting of medium and upper tobacco break-ups, which allows improving the technological efficiency and reliability of the process;

2. There were obtained the expressions characterizing the trajectory and absolute velocity of the arbitrary point of the cutting edge of a small drum;

3. Analysis of obtained dependences allows making the conclusion that at the cut a leaf will remain in the area of leaf separation and it will allow increasing the harvest.

\section{References}

1. S.K. Papusha, S.V. Belousov, A.E. Bogus. V.I. Konovalov, Theoretical studies of the tobacco stalk interaction with the leaf-separating unit, International Journal of Applied Engineer-ing Research (IJAER), Volume 11, Number 8 (2016)

2. Lepshina A.I., Belousov S.V., Means of minor mechanization as a basis for modern peasant farms and small farms in small forms of management, Polytechnical network electronic scientific journal of the Kuban State Agrarian University, No. 109. P. 392415 (2015)

3. E.I. Vinevsky, G.G. Maslov, E.I. Trubilin, Innovative system of technological complexes for the production of tobacco, Proceedings of the Kuban State Agrarian University - Krasnodar, No. 2, p. 151 (2008)

4. E.I. Vinevsky, G.V. Gromov, A.V. Ognianik, S.K. Papusha, E.V. Shidlovsky, N.N. Vinevskaya, R.N. Bukatkin, Some physical and mechanical properties of plants of native tobacco varieties, Collected scientific works of the All-Russian Scientific Research Institute of Tobacco, Makhorka and Tobacco Products - Krasnodar, No. 117, 203-208 (2008)

5. E.I. Vinevsky, A.E. Lysenko, I.I. Dyachkin, N.N. Vinevskaya, G.V. Popov, A.I. Petriy, S.K. Papusha, K.G. Gromov, E.V. Shidlovsky, A.V. Ognianik, New technique for tobacco growing, Achievements of science and technology of the agro-industrial complex, No. 6, p. $42-45$ (2007)

6. Pat. 2311013 Russian Federation, IPC A01D 45/16. Tabakouborochny combain [Text] / E.I. Vinevsky, E.V. Shidlovsky, N.N. Vinevskaya, I.B. Poyarkov, A.I. Petriy, I.I. 
Dyachkin, S.K. Papusha; applicant and patent holder of the GNU VNIITTI. - No. 2006106854/12; claimed. 06/03/2006; publ. 27.11.2007, Bul. № 33. - 7 with .: ill.

7. Pat. 63164 Russian Federation, IPC A01D 45/16. Technological scheme for harvesting tobacco leaves and preparing them for drying [Text] / EI Vinevsky, AE Lysenko, NN Vinevskaya, I.I. Dyachkin, I.B. Poyarkov, A.I. Petriy, S.K. Papusha, O.O. Nikolov, E.V .Shidlovsky, A.V. Ognianik; applicant and patent holder of the GNU VNIITTI. No. 2006119339/22; claimed. 06/01/2006; publ. 27.05.2007, Bul. № 15. - 6 with .: ill.

8. Pat. 2312486 Russian Federation, IPC A01D 45/16. Apparatus for separating tobacco leaves [Text] / S.K. Papusha, E.I. Vinevsky, A.E. Lysenko, I.B. Poyarkov, I.I. Dyachkin; applicant and patent holder of the GNU VNIITTI. - No. 2006119254/12; claimed. 06/01/2006; publ. 20.12.2007, Bul. № 35. - 5 p .: ill.

9. Pat. 2335117 Russian Federation, IPC A01D 45/16. Apparatus for separating tobacco leaves [Text] / S. K. Papusha, E. I. Vinevsky, IB Poyarkov, A.E. Lysenko, I.I. Dyachkin; applicant and patent holder of the GNU VNIITTI. - No. 2005128356/12; claimed. 12.09.2005; publ. 10.10.2008, Bul. № 28. - 7 with .: ill.

10. S.K. Papush, V.I. Konovalov, E.I. Vinevsky, Theoretical study of the interaction of the tobacco stem with a li-stootdelitelnym device, scientific support of innovative technologies of production and storage of agricultural and food products: Collection of materials of the III All-Russian scientific-practical conference of young scientists and graduate students. All-Russian Research Institute of Tobacco, Makhorka and Tobacco Products. - 2016. P. 176-183.

11. E.I. Trubilin, V.I. Konovalov, Course stability of disk implements, In the collection: Scientific and technological progress in agribusiness: problems and prospects International scientific and practical conference, within the framework of the XVIII International Agro-Industrial Exhibition "Agrouniversal 2016". . 2016. P. 114-119.

12. E.I. Trubilin, V.I. Konovalov, Course stability of disc-type soil-cultivating tools, In the collection: Scientific support of the agro-industrial complex edited by. A. G. Koshchaev. 2016. P. 249-250.

13. A.N. Shaporev, V.I. Konovalov, Course stability of disk harrows, In the collection: Scientific provision of the agro-industrial complex Collection of articles on the materials of the IX All-Russian Conference of Young Scientists. Responsible for the issue: A.Г. Koshchaev. 2016. P. 419-421.

14. E.I. Trubilin E.I., K.A. Sokht, V.I. Konovalov, V.V. Kravchenko, Deepening ability of disc harrows and lushchilniki, Rural mechanic-nizator, No. 11 (57). Pp. 14-15 (2013)

15. E.I. Trubilin, KA Sokht, VI Konovalov, Increase of technological efficiency of disk harrows, Rural mechanizer - M .: Iz-vo. "Niva", No. 3 (49), pp. 8-9 (2013)

16. E.I. Trubilin, K.A. Sokht, V.I., Konovalov, Increase of technological reliability of disk harrows and lushchilniki, Engineering and equipment for the village - Iz-vo. "The Russian Research Institute of Information and Technical and Economic Research on the engineering and technical support of the agro-industrial complex.", No. 6, p. 12-15 (2013) 